\title{
ESTUDIOS SOBRE EL POEMA EN PROSA
}

\author{
Carlos JIMÉNEZ ARRIBAS
}

Grupo de Investigación del SELITEN@T (UNED)

Resumen: El articulo se centra un los principales libros y artículos que han estudiado el poema en prosa en los últimos cincuenta años. Muchos de estos estudios se aproximan a la cuestión desde un punto de vista histórico, puesto que esta materia presenta no pocos problemas desde el punto de vista teórico. El artículo, en definitiva, versa sobre la tradición francesa en este campo, la relevancia del poema en prosa en América así como de su importancia y estudio en América Latina y en España.

Abstract: The article focuses on the major books and some of the articles that have studied the prose poem in the last fifty odd years. Most of these favour a historical approach, since the subject poses quite a few problems from a theoretical point of view. The article is focused on French tradition, the relevance of the American prose poem and its study as well as the impact of the prose poem in South America and Spain.

Palabras clave: Poema en prosa, España, América Latina.

Key words: Prose poem, Spain, South America. 
Pese a la carencia en España de trabajos teóricos sobre el poema en prosa, recientemente han aparecido entre nosotros estudios que venían siendo necesarios: la tesis de Benigno León Felipe (1999); o el libro Teoría del poema en prosa de María Victoria Utrera, en el cual esta autora achaca la escasa atención crítica despertada por el fenómeno a su asumida equivocidad genérica (Utrera, 1999: 17). Y no otra es la razón aducida para justificar el poco interés que suscita entre los propios poetas españoles (Villena, 1999: 18). En realidad, la práctica mayoría de trabajos que proponen una mirada más o menos exhaustiva al poema en prosa, especialmente los que lo hacen en forma de libro, parecen eludir el planteamiento final de una definición del mismo, optando más bien por el seguimiento del fenómeno a lo largo de la historia. Si, como afirma Francisco Abad, para hablar de un género debemos satisfacer unos mínimos de diseño e historia, teniendo en cuenta que "ese diseño es describible y su trayectoria historiable" (Abad, 1982: 116), parece que para el caso del fenómeno que nos ocupa, y dada la difícil tarea de su definición, el estudioso prefiera trazar un recorrido por los diversos exponentes antes que abordar lo que debería ser pórtico insoslayable a cualquier estudio: una descripción teórica.

\section{LA TRADICIÓN FRANCESA}

La pionera en su estudio, Suzanne Bernard (1959), a la que se cita con frecuencia en trabajos posteriores, habría marcado la senda a seguir con su monumental libro sobre el poema en prosa en Francia. La amplitud de su intento, eso sí, le permitía esbozar claves teóricas que en buena parte han demostrado su validez hasta la fecha. Por ejemplo, el establecimiento de una tríada mínima de definición en los parámetros de brevedad, unidad e integridad (Bernard, 1959: 15). Con menor ambición, pero con una deuda innegable para el proceder historicista, en su estela han surgido diversos estudios aplicados a otras tradiciones, también es notorio, menos ocupadas en la práctica del poema en prosa que la francesa.

En Francia se han sucedido las antologías desde que Maurice Chapelan diera a la luz la suya en 1946, la cual, fue seguida como modelo por Díaz-Plaja para el caso español una década más tarde. Ya Chapelan llama la atención sobre la inexistencia en lo 
francófono de una antología al respecto, hecho que le parece sorprendente. Es decir, incluso en Francia, leemos, la dejación del estudio del poema en prosa como forma teórica ha sido sintomática. Destaca, por lo demás, de sus páginas introductorias, una voluntad, no sólo por enumerar las calas evolutivas del fenómeno, sino también y sobre todo por establecer jerarquía de valores en los distintos pasos descritos. Véase si no cómo traza una valoración nítida ubicando a Bertrand como iluminador del pasado, a Baudelaire como reflejo subjetivo del presente $y$, finalmente, a Rimbaud dentro de una estatura mayor y proyectada hacia el futuro (Chapelan, 1946: XIV). Esta voluntad canónica será también el espíritu que informe la antología de Díaz-Plaja, y constituye un rasgo indudable de contemporaneidad. Como lo es también, en el caso de Chapelan (1946: XVI), apelar a la recepción como criterio definitorio último, si bien informado de más poder sugestivo y entusiasta que puramente descriptivo.

En su estudio sobre el poema en prosa anterior a Baudelaire, Pierre Moreau (1969: 6-8) plantea una tríada definitoria que, si bien no puede tener relación alguna con la de Bernard, cuya monografía ve la luz por aquellas fechas, recuerda la voluntad de definición en torno a tres líneas maestras, pero limitada al corpus que estudia, aún no formalizado. Su propuesta queda así limitada a cuestiones un tanto vagas, siendo los parámetros de ritmo, estilo e inspiración pobre bagaje para definir una forma genérica que, es cierto, aún quedaba lejos de constituirse en referente nítido de práctica literaria. $\mathrm{Su}$ estudio es un demorado repaso a los autores que, en las miradas diacrónicas al fenómeno, pasan sin excesivo detenimiento por estos ejercicios previos a Baudelaire. Peca, no obstante, de un exceso de entusiasmo a la hora de denominar como tal obras que, en estudios de mayor extensión, no conocen la mención directa de poemas en prosa. Toda vez establecida la tríada señalada, ritmo, estilo, inspiración, lejos aún de la más acendrada propuesta para el poema en prosa moderno, es comprensible que le quepan dentro del formato ejemplos dudosamente tomados como tales en un seguimiento total del fenómeno. Acompaña un apéndice publicado en la reedición diez años más tarde, que es la que manejamos, en el que con ambición estudia las relaciones entre poema en prosa y novela contemporánea; ambicioso, porque en esta adenda equipara el poema en prosa más reciente al denominado nouveau roman (Moreau, 1969: 49). Se confirmarían así los temores de Suzanne Bernard, quien por aquellos años quería intuir en el sesgo del poema en prosa hacia lo narrativo su mayor peligro como 
forma autónoma de expresión literaria. Al respecto, nos parece que las limitaciones definitorias que empañan la mirada de Moreau al poema en prosa proto-moderno, recuérdese, ritmo, estilo, inspiración, le llevan, al pasar por alto los criterios de formalización del mismo tras Baudelaire, a desvirtuar su objeto de estudio en la contemporaneidad.

Desde el asumido ámbito de la estilística, Monique Parent (1960) dedicó una monografía al poema en prosa. Su estudio se divide en tres partes: una primera centrada en aspectos teóricos del mismo, bajo el ambicioso título de La technique du poème en prose, y dos apartados más centrados en autores concretos: Charles Péguy y Saint-John Perse, este último desde un punto de vista exclusivamente temático. Una de sus aportaciones es el estudio estadístico de vocabulario, método deudor de su tiempo -la filiación para con M. P. Guiraud es explícita- y, en cierto sentido, próximo a las variaciones morfológicas y lexemáticas que, hará suyas en la aproximación al poema en prosa la semiótica de Michael Riffaterre. Se trata, en todo caso, de un estudio de iteraciones léxicas que venía abonado por la concepción de orfandad isomórfica desde la que se vislumbra el objeto de estudio en ambos enfoques. Parent, en concreto, cae así en un exceso normativo de las posibilidades expresivas, además del típico de la época para el análisis de textos: el écart, la desviación -literalmente distancia- para con el lenguaje no literario. Su aportación, tanto para un recto entendimiento del poema en prosa desde un punto de vista genérico como teórico, no nos parece significativa.

En el mismo año de publicación del libro de Parent, Louis Guillaume (1990: 83108) pronunció una conferencia en la Sorbona acerca de la evolución del poema en prosa, recogida posteriormente en un volumen en su honor. Su alocución se inicia, es significativo, reconociendo que el verso no es la forma de expresión privativa de la poesía. Deja, por otra parte, clara la distinción que debe hacerse entre el poema en prosa moderno y los así denominados en el siglo XVIII, distingo que, en aras de un mayor y más antiguo enraizamiento del fenómeno, no siempre es efectuado con nitidez. Guillaume (1990: 87) no duda en calificar de pionero a Parny y sus Canciones malgaches, poniendo el acento sobre un rasgo que se repetirá: la hibridación, en este caso entre exotismo y mistificación. Obsérvese que ha datado el nacimiento del poema en prosa aun antes del Romanticismo. La contribución de Bertrand, según esto, sería dotarle al formato de una de sus más férreas señas de identidad: la brevedad. De 
hecho, ahí cifra su modernidad, no en la temática, sino en la forma (Guillaume, 1990: 89). Aportación de novedad es marcar el paso dado por Baudelaire, en el contenido y en lo formal, hacia la modernidad como el establecimiento del poema en prosa prosaico, distanciando con este nuevo epíteto el ejercicio baudeleriano del modelo inspirado en la balada propiciado por Bertrand. El poema en prosa prosaico, feliz referente terminológico de la famosa epístola en la que Baudelaire pide una forma nueva de poetizar, atiende al carácter urbanita que será seña de identidad del fenómeno. También es de interés cómo ordena la tríada inicial de autores -vemos que, dada la unanimidad en los formantes, lo novedoso del análisis se basa en su jerarquización, el modo en que se aúnan $\mathrm{y}$, diríamos, se leen como tradición-: Bertrand habría creado el género, Baudelaire informa la serie de modernidad, Rimbaud le otorga nueva gramática (Guillaume, 1990: 93). Su intento de definición, por lo demás, no se aleja de la tripartita canónicamente establecida por Suzanne Bernard: integridad, gratuidad, brevedad. En definitiva, una síntesis de interés, personal en sus momentos más preclaros, adscrita a la convención inaugurada por Bernard en sus conclusiones.

Una compilación que no duda en ofrecer su visión personal al respecto es la de Luc Decaunes (1984), Le Poème en prose. Anthologie (1842-1945). Su autor, poeta de considerable prestigio que incluye textos suyos a modo de post-scriptum, no duda en decantarse por la variedad más breve del poema en prosa, encumbrando en su particular lectura de la tradición el ejercicio de Max Jacob, basando la práctica del mismo en torno a la tríada -ya a estas alturas toda una Trinidad- brevedad, intensidad, gratuidad. De más reducida apoyatura teórica que otras antologías, la de Decaunes ofrece como punto de principal interés el ser la asumida lectura de un practicante autorizado del poema en prosa que no duda en rescatar los mejores textos y, dentro de una ya vasta tradición, en alinear éstos en las filas de la brevedad textual militante. Desde el punto de vista histórico, destaca la división del material que recoge en dos etapas, de manera aproximada coincidentes con los dos siglos, XIX y XX, en los que el poema en prosa ha ocupado con intensidad y vigencia a los poetas franceses.

Un libro sobre el poema en prosa que nace como empresa divulgativa -su título, Lire le poème en prose, ilustra lo propedéutico de la intención- pero que sin embargo logra cotas no desestimables de introspección teórica sobre el mismo es el de Michel Sandras (1995). Su alcance queda, eso sí, circunscrito al caso francés, lo cual no es 
óbice, como veremos, para garantizar nómina nutrida de exponentes y un corpus lo suficientemente amplio en su desarrollo histórico. Es de utilidad la antología que cierra su estudio, además de la guía progresiva de trabajos teóricos sobre el fenómeno que Sandras ofrece, y comenta, como colofón a su libro, de enorme interés para quien se acerca a esta esquiva modalidad de escritura.

Inmediatamente posterior al libro de Sandras, el de Yves Vadé (1996) se ofrece como una de las constantes en el acercamiento al poema en prosa: estudio teórico seguido de antología. Sea porque la dificultad de definir con certeza nuestro objeto de estudio requiere el apoyo práctico de los textos que sobre el particular puedan arrojar la luz de su existencia, sea porque la compilación de éstos ayuda a su propia canonización $\mathrm{y}$, de suyo, a un entendimiento menos cuestionable del poema en prosa como género, el caso es que abundan los estudiosos que abordan la cuestión con el recurso, tras el proceder teórico, a una crestomatía. Compilación que, en muchos casos, sirve para ilustrar una determinada línea estética defendida por el antólogo, como es el caso de la personalísima obra de Decaunes repasada anteriormente. Habría que decir, según esto, que la de Vadé -cuyo título completo, Le poème en prose et ses territoires, no deja duda alguna acerca de la ambición compiladora- es la antología de poesía en prosa francesa más completa y documentada de las aquí consultadas. Al antólogo se le debe una extensa nómina de poetas reunidos $\mathrm{y}$, además, su cabal estudio tanto de un modo histórico, en el que cada autor ve cifrada su contribución al desarrollo diacrónico del poema en prosa, como en la antología final, organizada por temas y de extensión superior a otras compilaciones. Vadé acompaña su recorrido además de una valiosa cronología, si bien se echan en falta más entradas bibliográficas -pero no debemos olvidar el carácter divulgativo de la mayor parte de estas antologías-, y en el proceder teórico asume demasiado alegremente la tensión como criterio definidor del poema en prosa, extremando un tanto sus conclusiones al respecto. Su antología, insistimos, es de gran valor para desgranar muchos de los presupuestos teóricos que definen el poema en prosa y ofrece, además, un comprehensivo panorama de las vicisitudes y crecimiento del fenómeno en las letras francesas.

También del año 1996 es el libro de Natalie Vincent-Munnia, Les premiers poèmes en prose : généalogie d'un genre. Dans la première moitié du dix-neuvième siècle français. Pese a centrarse en el periodo que recoge en su título, esta autora aporta 
consideraciones de sumo interés para el estudio del poema en prosa en su conjunto. Justifica su proceder por la atención que merecen los poemas en prosa franceses de la primera mitad del XIX como articulación y génesis que precede al impulso genérico dado por Baudelaire. Hay que agradecerle, además, la voluntad de poner en relación lo investigado con la teoría de los géneros, siendo de relevancia los testimonios que aporta de críticos y autores que desde el XVIII se ocuparon de la recepción de fenómeno: viene a demostrar lo intenso y prolongado, también lo antedatado, del debate. Ofrece asimismo cumplida evolución del término poema en prosa y su progresión designativa: de la épica en sus albores dieciochistas al lirismo prerromántico, muestra del arduo pero fructífero acarreo que dará como resultado la elevación expositiva del discurso prosístico. Retrotrae, además, la importancia de las traducciones en la configuración del fenómeno al siglo XVIII y la traslación allí de obras clásicas. Demuestra, por otra parte, los escarceos protagonizados por los primeros poemas en prosa, el término es suyo, entre la fluidez del discurso prosístico y la discontinuidad e iteración del poético. Todo ello ilustrado con el prolijo análisis de los textos en cuestión. Pero quizá lo más interesante sea el estudio que lleva a cabo de la recepción que en su día conocieron estas primeras muestras de poemas en prosa por parte de lectores, escritores y académicos, y ello prolongado hasta fecha reciente, es decir, ilustrado por la evolución diacrónica de esa recepción. Las conclusiones que saca de este cotejo en la recepción constituyen lo más granado de su aporte: demostrar la intrínseca relación entre lo desapercibidas que pasaron las primeras muestras y su falta de estatura genérica diferenciada entonces. Su bibliografía es, además, completa y cuenta con una clasificación muy útil.

\section{LAS MONOGRAFÍAS NORTEAMERICANAS}

John Simon (1987) dedica la mayor parte de sus esfuerzos a la labor de seguimiento histórico centrándose en el siglo XIX europeo, un europeísmo circunscrito a los sistemas francés, alemán e inglés. Este estudioso traza allí un mapa exhaustivo y preciso de los exponentes, pero, como él mismo admite, queda lejos de ofrecer un planteamiento teórico, una definición coherente de qué sea un poema en prosa. 
Tras el despliegue de artillería taxonomizadora llevado a cabo, la asunción de limitaciones es conmovedora, pero escasamente convincente. Los mayores logros hay que buscarlos precisamente en las páginas que, siguiendo un acertado comparatismo, ponen en relación unas tradiciones con otras.

De mayor ambición en sus planteamientos, también menos apocado en sus conclusiones -quizá porque ya desde el mismo título se elude entrar en la difícil cuestión genérica- es el libro de Stephen Fredman (1990) Poet's Prose. The Crisis in American Verse, originalmente publicado en 1983, cuyo interés para críticos y poetas aconsejó que se llevara a cabo esta segunda edición. Distanciándose del modelo baudeleriano de poema en prosa -breve, urbanita, irónico y tensado en su dicción y relación con el mundo-, Fredman se centra en ejemplos más extensos y que no esquivan lo metafísico ni lo autobiográfico en su planteamiento. Pese a ello, en ningún momento habla este estudioso de prosa poética, socorrido marbete que hace flaco favor al recto entendimiento. Desde aquí, además de celebrar las conclusiones de Fredman en torno al par escritura y verdad, valoramos las claves que su modelo podría ofrecer para una aproximación, por ejemplo, al juanramoniano Espacio, de tan dificultosa clasificación como poema en prosa pero, creemos, difícilmente entendible de algún otro modo. Un espíritu similar, por cuanto que no centran su objetivo en el poema en prosa propiamente dicho, sino más bien en la prosa de filiación poemática, informa los trabajos de Ron Silliman $(1986,1987)$, quien ha dedicado páginas de relevancia al gusto por la prosa de gran parte de la poesía norteamericana última. Se trata además de la mirada crítica de un aventajado poeta sobre el fenómeno, enmarcada dentro de un proyecto mayor de revisión de la tradición lírica occidental. Véase, si no, su labor teórica de definición de unos parámetros de suficiencia en torno a la unidad oracional equiparables a la rica retórica del verso.

Para el caso del poema en prosa, la literatura comparada se presenta como disciplina especialmente idónea en su atención a diversos sistemas. Jonathan Monroe (1987: 37), por ejemplo, desde el comparatismo que informa su estudio y con la monografía de Suzanne Bernard en mente, desaconseja cualquier enfoque centrado en los exponentes de una única tradición por existir, según él, en un trabajo de tales características, un poso excesivo de historicismo, lastre que sólo vendría a desvirtuar el cabal entendimiento del poema en prosa, una modalidad de escritura disgregadora y dispersa, poética y geográficamente, como pocas. Su estudio consigue aunar un mínimo 
de rasgos definitorios de la forma poema en prosa a lo largo de varios periodos, tradiciones y poetas. La tesis principal del libro, el potencial del poema en prosa para criticar desde la praxis el excesivo solipsismo de la lírica más estrechamente entendida como romántica - egotista y autotélica-, se ve progresivamente sustentada por los diversos modelos que analiza, desde el fragmento romántico al poema en prosa ya plenamente constituido en el siglo XX.

Monroe tenía bien presentes en su análisis las tesis de Bajtín sobre la naturaleza polifónica de la novela, un género al que constantemente remite el poema en prosa en su libro. En esa misma dirección se encuentran Richard Terdiman (1985), quien incluye un capítulo sobre el poema en prosa en su análisis del discurso y el contradiscurso en la literatura francesa del XIX, en el que nuestro objeto de estudio ocupa un lugar destacado como frontera o límite de confrontación política desde lo textual; y Margueritte Murphy (1992), quien lleva por su parte las enseñanzas bajtianas y el papel subversivo del poema en prosa a las letras anglófonas. El título de su libro, A tradition of Subversion. The Prose Poem in English from Wilde to Ashbery, no deja lugar a dudas, si bien desmiente en su contenido el perfil historicista que aventura el recorrido de uno a otro poeta. Este matiz, la renuncia a un desarrollo histórico del análisis, es la diferencia principal que la autora reconoce para con los modelos asumidamente marxistas de Terdiman y Monroe.

En un trabajo más reciente, The American Prose Poem, Michel Delville (1998) se centra en el poema en prosa dentro de una misma tradición, la norteamericana, y, de nuevo, erige su vigencia crítica no tanto en la elaboración de un decálogo al uso como en el seguimiento del fenómeno espigando referentes de continuidad no necesariamente histórica a través de décadas, autores, obras y promociones de poetas. La reducción del marco geográfico e histórico sirve a Delville para profundizar más en las claves teóricas de cada uno de los modelos estudiados. Si tenemos en cuenta la renuncia expresa a elaborar una teoría al uso, los resultados teóricos obtenidos son más que aceptables. La crítica, no obstante, no ha dejado de recordar esta fórmula evasiva como una desventaja (Elshtain, 2001: 171).

Otra lanza rota a favor de una perspectiva comparatista es la de Steve Monte (2000), quien en su libro Invisible Fences. Prose Poetry as a Genre in French and American Literature traza el cotejo precisamente entre las tradiciones más significadas al respecto, a saber, la francesa y la nortea mericana. Su defensa de este modo de 
proceder es, así, específica y busca llegar a un entendimiento más preciso del fenómeno precisamente comparando diferentes épocas y lugares (Monte, 2000: 1). Su aclaración de intenciones continúa, por cierto, con otra constante en los estudios al uso: la de ajustarse a una perspectiva más historicista que puramente teórica. Su estudio se abre con un valioso repaso diacrónico a los que le han precedido, ubicando cada trabajo previo sobre el poema en prosa en perspectiva contextualizada. Es de valorar, asimismo, el esfuerzo que realiza este estudioso por abandonar el tan llevado carácter subversivo del fenómeno, esgrimido habitualmente más como excusa para no entrar en materia descriptiva que como presupuesto de validez metodológica, lo que a la par oculta cuestiones de mayor relevancia acerca de su propia naturaleza. Igualmente, valoramos su denuncia de muchos otros tópicos que empecen, so capa de hacerle mayor justicia, un entendimiento desprejuiciado del poema en prosa, verbigracia, la lectura estrechamente postmoderna que ve en él un exceso de claves como escepticismo y falta de cerrazón formal fuerte (open-endedness) en su propuesta estética. Monte traza además un valioso recorrido por la propia historia del término poema en prosa y los distintos referentes que ha convocado, también los diversos usos con los que ha entrado en conflicto. Su aproximación a la teoría de los géneros es exhaustiva, aunque en ocasiones el medio ostente la categoría -y la extensión- de fin. Es importante también su intento de introducir criterios de historicidad en los planteamientos de género, y muy de interés el estudio valorativo y comparativo de antologías, tanto en Francia como en EEUU, que incluye al final.

Los intentos de definición teórica para el poema en prosa parecen haber venido, más que en forma de monografía, desde un acercamiento al mismo en artículos o capítulos significativos dentro de un marco mayor. Sin duda el más ambicioso de éstos fue el de Michael Riffaterre (1979). Allí, retomando el guante lanzado por Suzanne Bernard a la hora de proclamar la autosuficiencia genérica del poema en prosa, Riffaterre se propone un estudio del fenómeno en verdadera profundidad que sirviese además para fundamentar el proceder teórico del modelo semiótico. Sus resultados no son desestimables, si bien el alcance total del intento peca de excesiva complejidad. Un discípulo suyo Stamos Metzidakis (1986) amplió esas conclusiones en forma de libro, llevando hasta ciertos extremos la principal aportación de Michael Riffaterre: la proclividad intertextual del poema en prosa. Posteriormente, el propio Michael Riffaterre incluiría un artículo mucho menos aprovechable por su prolijidad en el 
libro editado por Mary Anne Caws y Hermine Riffaterre (1983), íntegramente dedicado al poema en prosa francés. La asunción por parte de los editores de este marco geográfico ya en la década de los ochenta, cuando muchos poetas norteamericanos se habían significado en el uso del poema en prosa, da cuenta de la importancia que la tradición francesa tiene en cualquier acercamiento al fenómeno. Allí se abordan obras muy concretas de poetas específicos, ofreciéndose un panorama de alta introspección crítica lejos aún, no obstante, de la propuesta teórica más deseada: responder a la pregunta ¿qué es un poema en prosa?

\section{ESTUDIOS DEL POEMA EN PROSA EN ESPAÑA}

Sin duda a esta imposibilidad para el seguimiento de tan escurridiza forma poética en las letras españolas aludía Pedro Aullón de Haro (1979: 136) al desestimar un detenimiento por extenso de la crítica en esta modalidad de escritura en España que fuera más allá de la llamada generación del 27. El esfuerzo de Aullón de Haro quedaba patente en el título de su trabajo: se centraba en los exponentes más tempranos, de la segunda mitad del XIX, y el sucesivo desarrollo de esta forma poética en las primeras décadas del siglo XX. Su planteamiento, ya desde el inicio, aborda los aspectos más espinosos de la cuestión, tales como la cuestión del género, los criterios de brevedad e integridad, la intención creadora, la necesidad, en fin, de separar el poema en prosa de hibridaciones narrativas comúnmente confundidas con él (Aullón de Haro, 1979: 119). El grueso del trabajo está dedicado, sin embargo, a buscar los primeros brotes de una prosa atenta a lo poético y hacer un seguimiento histórico del fenómeno, también de su exacta ubicación con respecto a la tradición francesa. Y es que el poema en prosa, asumía Aullón de Haro en 1979, entre nosotros sólo contaba con el incipiente beneplácito de autores jóvenes. Esta escasez en su práctica es lo que sin duda le lleva a desaconsejar la atención crítica al fenómeno en lo contemporáneo. Él mismo se ha ocupado con posterioridad del poema en prosa en diversos libros y artículos, si bien nunca con la centralidad de este trabajo inicial. Recogemos este material bibliográfico en las referencias al respecto, a la vez que consignamos su labor como director de una tesis doctoral sobre el poema en prosa: la de Marta Agudo recogida más adelante. 
Pero el esfuerzo pionero de atención al fenómeno entre nosotros es la Antología del poema en prosa de Díaz-Plaja (1956), aun hoy un trabajo fundamental para el estudio del poema en prosa entre nosotros. Se le deben dos aportaciones fundamentales: el esbozo de una teoría del poema en prosa -su estudio se inicia con una inequívoca "Estética" del mismo- y algo que muchos años más tarde ha devenido criterio fundamental para los estudios literarios: la elaboración de un canon. Por lo que respecta al esfuerzo teórico, no se le puede negar cierta exhaustividad en el intento, algo que le lleva a recoger los siempre procelosos estudios de los valores métricos en el discurso prosístico. Su visión del poema en prosa como discurso eminentemente impresionista, por lo demás, parece difícilmente sostenible hoy, vista la nómina de exponentes que se alejan del rasgo pictórico, sin duda de importancia en los albores. Finalmente, la adscripción de la expresión poética en prosa a la espontaneidad acerca su estudio a aquella apreciación que considera al poema en prosa menos sujeto a pautas de composición que su homónimo en verso. En definitiva, es el recorrido por la literatura española de la primera mitad del siglo lo más interesante de su libro. Especialmente por la fina intuición que muestra en el espigado de exponentes de un mismo autor -la sabia elección de unos textos de Hinojosa en detrimento de otros alejados del modelo, por ejemplo-, y la definición de los distintos grupos poéticos conforme éstos se ubican ante el poema en prosa. Como vimos, cuando se trata de estudiar el poema en prosa, parece que el proceder histórico viniera siempre a ofrecer frutos más sustanciosos que el estrictamente teórico. El intento es, en resumidas cuentas, encomiable. Especialmente si consideramos la escasez de auténticos poemas en prosa concebidos como tales por sus autores con los que el antólogo contaba para hacer su compilación. No es de extrañar, pues, la asumida mirada a otros ámbitos -la novela, por ejemplo- con la siempre dudosa intención de rescatar fragmentos legibles como poemas en prosa.

María Victoria Utrera (1999), a quien ya hemos aludido, ha aplicado con resultados notables, por su parte, un modelo que podemos considerar en lo básico historicista al seguir la peripecia del poema en prosa de forma cronológica en sucesivas sistematizaciones geográficas. Su trabajo viene a cubrir un hueco importante en la nómina de estudios dedicados al poema en prosa al ubicar los exponentes hispánicos del fenómeno dentro de un marco mayor que los abarca y cualifica. Al incorporar también planteamientos teóricos, verbigracia, el de Leopoldo Alas, Clarín, que nutren una mínima tradición teórica de seguimiento del fenómeno en lo hispánico. Comienza esta 
autora centrándose en los aspectos relativos al universo expresivo de la prosa, para trazar a continuación un desarrollo del poema en prosa en el siglo XIX especialmente en Francia, con alusiones breves pero claras a otras tradiciones de importancia como la norteamericana, o en menor medida la británica o la alemana. Con ello el lector de habla hispana cuenta con un panorama general bastante preciso de la evolución del poema en prosa y puede así situar en este desarrollo las distintas muestras del mismo procuradas por su tradición. Cabe objetársele a este documentado trabajo la ausencia de unas páginas finales en las que se recapitule y proponga una mínima teoría del poema en prosa, tal y como promete el título de la obra. Empresa harto difícil dada lo elusivo del fenómeno. También podría pensarse que el vuelo cronológico se queda corto, vista la nómina de exponentes posteriores al modelo cernudiano que ha deparado nuestra tradición, algunos de los cuales la autora incluye en epígrafe final. No obstante, la magnitud del trabajo parece aconsejar que se atendiera primero a un desbroce y mínima sistematización de la prehistoria e historia del poema en prosa con atención especial al marco francés, sin duda el que más influencia ha tenido en los poetas hispanohablantes estudiados por esta autora aquí, y en gran parte de los que vendrían después. Sólo así parece lícito encarar ahora estudios de las poéticas en prosa de autores de la segunda mitad del siglo XX.

Dentro de criterios estrictamente geográficos hay que englobar la Tesis Doctoral de Benigno León Felipe (1999), El poema en prosa en España (1940-1990), también presentada con su correspondiente antología, aunque este estudioso aclara que la compilación en su caso ha sido un paso previo para acotar el campo que luego analiza en el estudio (León, 1999: 14). León recoge minuciosamente aquellos autores que se han dado al cultivo del poema en prosa en España y en castellano en la segunda mitad del siglo XX. El amplio margen cronológico hace que, salvo excepciones como Juan Ramón Jiménez, Cernuda, o Valente, no tenga margen para extenderse más de unas pocas páginas en cada uno de esos exponentes, pero el mapa resultante es de referencia indiscutible. La ordenación que propone de su antología, además, y el índice que ofrece al final, permite un rastreo exhaustivo de las fechas de publicación de libros de poemas en prosa en España, independientemente de los debates, ya caducos algunos, generacionales. Se puede ver así los momentos de mayor afloración de exponentes. De utilidad similar son las páginas en las que relaciona nómina de poetas que publican poema en prosa y las antologías en las que aparece recogida su obra. Se le debe también 
un interesante rastreo de los fenómenos de prosificación del verso y poetización de la prosa anteriores al siglo XIX, y un repaso que es necesaria rectificación a quien se erige en su precedente: Díaz-Plaja y la única otra antología de poesía en prosa en lo español. Hay que considerar además que sus capítulos sobre Juan Ramón Jiménez y sobre Cernuda suponen síntesis valiosa del estudio de ambos, y una delimitación clara y ambiciosa del problema del género en el caso del primero. Por lo demás, el lector encontrará cumplida cuenta de quién publicó poesía en prosa en España en la época estudiada, cuándo lo hizo y qué modelo del mismo estableció. La antología que acompaña el estudio, más bien al revés, es sin duda lo más granado del trabajo de Benigno León, donde declara explícitamente haber puesto su mayor ambición, y sólo queda lamentar que circunstancias editoriales hayan retrasado su aparición entre nosotros, a día de hoy aún pendiente. No dudamos de que será obra de referencia. Su dedicación le ha llevado además a estudiar el poema en prosa en las Islas Canarias (León, 2000), con nueva antología, más una perspectiva de conjunto en la primera mitad del siglo XX (León, 2002b), y la obra en prosa de José Ángel Valente (2002).

Marta Agudo Ramírez (2003), en su Tesis Doctoral, La poética romántica de los géneros literarios: el poema en prosa y el fragmento. Teoría europea y su especificación en España, estudia el poema en prosa y el fragmento en el siglo XIX en España. El director de este trabajo, como ya apuntamos antes, es el profesor Pedro Aullón de Haro, pionero en el estudio del fenómeno poético en prosa entre nosotros. La aportación de Marta Agudo es fundamental, pues sienta las bases de una práctica que conoció un auge quizá tardío pero contrastado en lo que a las aportaciones de calidad literaria se refiere. La autora, que ha documentado su estudio con recurso abundante a la teoría de los géneros románticos en Europa y rescata textos de valor fundamental para la historia del fenómeno en España, propone, además, un planteamiento teórico, y nunca están de más en el proceloso ámbito de la poesía en prosa, de enorme sugerencia. Nos referimos a la formalización en desarrollo pendular del ideario del poema en prosa, su oscilación, por un lado, entre los polos de narratividad y ensayo en lo desatado de su propuesta textual, y, por otro lado, a una sentenciosa concentración en fenómenos como el aforismo, la literatura proverbial, o la misma greguería ramoniana. Partiendo siempre de un núcleo necesario de lirismo, se dispone la posibilidad, según esto, de estudiar el fenómeno bajo una cartografía de puntos cardinales en lo genérico. El norte y sur del poema en prosa alude inteligentemente, así, a la diversa proclividad que ostentan los 
distintos exponentes, el septentrión de lo narrativo, o bien una suerte de sur cifrado en cerrazón conducente a lo paremiológico, y designa con suficiencia una panorama de especulación genérica de enorme complejidad. A su Tesis se le debe, además, la feliz idea -lo que bien mirado es una necesidad- de estudiar de forma conjunta dos fenómenos emparentados en la raíz del romanticismo europeo y de todo el edificio estético de la modernidad: fragmento y poema en prosa. La nómina de textos que esta estudiosa y poeta rescata, su volumen y rigurosa novedad, hacen de su trabajo un mojón inexcusable en la precaria tradición de estudio del poema en prosa, incompleta también entre nosotros.

La literatura catalana mostró desde finales del siglo XIX, coincidiendo con el fervor simbolista por el poema en prosa en Francia, un cultivo continuado del mismo. También en el aporte crítico contamos con dos estudios recientes que se ocupan del fenómeno en las letras catalanas. En Una aventura poética moderna (El poema en prosa en la literatura catalana), Paulí Arenes (1998) traza un riguroso recorrido por el trayecto que llevó a los primeros cultivadores catalanes del fenómeno, Santiago Rusiñol, Alexandre de Riquer, y Adrià Gual, desde las fuentes simbolistas francesas hasta su propio ejercicio en sendos libros de poemas en prosa. Lo más granado de su estudio, que hay que entender exclusivamente circunscrito a la literatura modernista, pese a lo ambicioso del título, es ese rastreo, no sólo de posibles fuentes, sino de la motivación de estos autores a la hora de escribir poesía en prosa. Su planteamiento cobra interés en el cotejo de revistas catalanas del fin de siglo y en el interrogante suscitado a lo largo de su estudio y desde diversos puntos de vista: ¿eran conscientes estos autores de estar escribiendo poemas en prosa con plenitud de intención pragmática? Su trabajo es una contribución de valía al estudio del modernismo catalán, y ofrece un panorama de rigor y profundidad en el entronque e implantación del poema en prosa en Cataluña a través de la rica influencia que la literatura ejerció entonces con especial fuerza. El final del libro, sin embargo, dedicado al estudio de presupuestos teóricos, es demasiado breve para lograr aportaciones de interés. Allí se limita el autor a glosar, bien que dialéctica y no acomodaticiamente, algunos de los asertos de Suzanne Bernard. La importancia de este estudio, insistimos, radica en la modernidad del planteamiento pragmático: cuando cuestiona con amplitud de miras y profundidad la total conciencia del autor que, casi adánicamente, decide entregarse con fervor pionero al cultivo de un nuevo fenómeno literario. 
Un proyecto también centrado en el poema en prosa practicado en la literatura catalana es la antología de Sam Abrams (2001) Tenebra blanca, que se ocupa en concreto de la época contemporánea, dando entrada inicial a J. V. Foix, para, desde la cima que constituye este autor, llegar hasta poetas nacidos en los años setenta. Hay que decir que lo primero que sorprende es el enorme número de poetas antologados, más de ochenta, lo que da una idea de la importancia que nuestro objeto de estudio conoce en la literatura en catalán. El prólogo de Abrams ofrece una síntesis interesante, si bien lejos del enjundioso estudio con que encabeza su antología Sandras, un posible precedente. No obstante, el de este último debe su extensión a la voluntad pedagógica que supone trazar una historia del fenómeno, mientras que Abrams se ocupa de recoger el ejercicio contemporáneo al respecto. Supone aportación de interés retrotraer la prehistoria del subgénero (Abrams, 2001: 13), como él lo llama, a fecha tan temprana como el siglo XVII. Es de interés también su énfasis en el cuestionamiento del papel exclusivo que el verso ostentaba para la poesía, algo que ya protagonizaron los ilustrados, además de signar el triunfo de la prosa como vehículo expresivo. Se trata de afirmaciones comúnmente halladas en los estudios al uso, pero que Abrams hilvana en una síntesis de utilidad y relevancia. A partir de aquí, su explicación de la evolución del fenómeno nos parece menos original, por limitarse a seguir los pasos y efectos ya sabidos: impulso romántico, traducciones, y el rescate del bernardino poème en prose involontaire (Abrams, 2001: 15) como inmediato precedente. Su revista diacrónica culmina con un hecho que parece significativo: la concesión del Pulitzer de literatura, el premio más preciado de los Estados Unidos en 1990 a The World Doesn't End, de Charles Simic, libro de poemas en prosa que, quizá no sea gratuito, ha sido dado a conocer entre nosotros en castellano por una editorial catalana. Su segundo apartado, no obstante, se inicia con el argumento del oxímoron, asumiendo una contradicción que no se sostiene sino como tópico todo lo sugerente que se quiera pero sin fundamento. Hablar de prosa y de poema como "termes absolutament excloents" (Abrams, 2001: 15) no es de recibo, ni siquiera pese a que se esfuerce inmediatamente por matizar lo complejo del fenómeno.

Dos antologías más nos visitan en estas páginas. Son sendos trabajos centrados en el poema en prosa hispanoamericano. La delimitación del objeto seleccionado ya ofrece un marco excesivamente amplio, e indeterminado -por ejemplo, ¿se incluyen exponentes españoles y brasileños?-. Se trata de dos títulos de los que hemos tenido 
noticia, pero nos resistimos a creer que no haya más. Sin duda los habrá de variedades breves de narrativa, microcuentos y microrrelatos, una forma genérica que parece campar a sus anchas por el mapa riquísimo del idioma en el subcontinente. Pero tanto, Luis Ignacio Helguera (1993) con su Antología del poema en prosa en México, como Jesse Fernández (1994), a cargo de El poema en prosa en Hispanoamérica, centrado exclusivamente en modernismo y vanguardia, presentan limitaciones. Es lógico en un intento encomiable de obra divulgativa como el que ocupa a ambos. En la primera de estas compilaciones se puede objetar por exceso; en la segunda por defecto. El título de la antología de Helguera, no obstante, al aludir al poema en prosa en México, parece justificar la inclusión de autores no estrictamente mexicanos que vivieron y publicaron sus poemas en prosa allí. A Jesse Fernández, por su parte, se le puede objetar la no inclusión de un autor como José Antonio Ramos Sucre, si bien el informado y sugerente estudio preliminar puede dar cuenta, con la claridad teórica y genérica de ideas al respecto que expone, de esta y otras ausencias. Estas dos últimas antologías muestran a las claras cómo el trasvase de autores y estudios de un lado al otro del Atlántico -una antología del poema en prosa hispanoamericano publicada en España, autores españoles engrosando las filas de una antología del poema en prosa en México-, es una constante en la historia literaria del idioma, además de una fuente insondable de enriquecimiento del mismo. Como precedente se puede buscar el de Darío a su paso por España, o el de Juan Ramón dejando huella de su predilección por la prosa en su etapa final en autores del cono sur; o el ejemplo de Ángel Crespo (1966), estudioso del fenómeno desde Brasil en tan temprana fecha.

Existen otros trabajos, especialmente artículos o epígrafes dentro de obras mayores dedicados al poema en prosa. Las referencias al mismo en diversos estudios sobre autores y obras diferentes son, igualmente, abundantes. Hemos querido traer a colación en este estado de la cuestión aquellos estudios que se han centrado en el tema de manera monográfica. Quizá sería de relevancia señalar, dentro del ámbito de la literatura española, los trabajos de Juan Manuel Rozas (1973), sobre la prosa azoriniana y la filiación poemática de algunos pasajes; el de Gonzalo Sobejano (1990), de similar voluntad para con La lámpara maravillosa de Valle Inclán; el de Millán Alba (1989) centrado en el sugerente ámbito del lirismo; o el documentado compendio de José Francisco Ruiz Casanova (1999) en su análisis del poema en prosa en la obra de creación de Ángel Crespo. Remito para una nómina de estudios más específica a mi 
estudio comparativo entre el poema en prosa y la ficción breve (Jiménez Arribas, 2001) y a la propia bibliografía recogida al final de mi tesis doctoral (Jiménez Arribas, 2004), dirigida por José Romera Castillo.

\section{REFERENCIAS BIBLIOGRÁFICAS}

ABAD, Francisco (1982). Los géneros literarios y otros estudios de Filología. Madrid: Cátedra de Lingüística General UNED.

Agudo RamíRez, Marta (2003). La poética romántica de los géneros literarios: el poema en prosa y el fragmento. Teoría europea y su especificación en España. Tesis Doctoral dirigida por el Profesor Pedro Aullón de Haro. Universidad de Alicante (inédita).

BERnARD, Suzanne (1959). Le poème en prose de Baudelaire jusqu'a nous jours. París: Nizet.

Chapelan, Maurice (1946). Anthologie du poème en prose. París: Julliard.

CRESPO, Ángel (1966). "Muestrario del poema en prosa brasileño". Revista de cultura brasileña $\mathrm{V}, 18,225-258$.

DECAUnES, Luc (1984). Le Poème en prose. Anthologie (1842-1945). París: Seghers.

Diaz-PlazA, Guillermo (1956). El poema en prosa en España. Estudio crítico y antología. Barcelona: Gustavo Gili.

FERNÁNDEZ, Jesse (1994). El poema en prosa en Hispanoamérica. Madrid: Hiperión.

Fredman, Stephen (1990). Poet's Prose. The Crisis in American Verse. Cambridge: Cambridge University Press, $2^{\mathrm{a}}$ edición.

Guillaume, Louis (1990). 'L'Evolution du poème en prose d'Aloysus Bertrand à nos jours" [Conferencia pronunciada en la Sorbona el 27 de febrero de 1960]. En Carnets de l'Association des Amis de Louis Guillaume 16, 83-108.

Helguera, Luis Ignacio (1993). Antología del poema en prosa en México. México: Fondo de Cultura Económica.

JiMÉNEZ ARRIBAS, Carlos (2001). "Minicuento y poema en prosa: un esbozo comparativo". En El cuento en la década de los noventa. Actas del X Seminario 
Internacional del ISLTYNT de la UNED, 704-711, José Romera Castillo y Francisco Gutiérrez Carbajo (eds.). Madrid: Visor.

- (2004). El poema en prosa en los años setenta en España. Tesis Doctoral dirigida por el Profesor José Romera Castillo. Madrid: UNED (inédita).

LEÓN FeLIPE, Benigno (1999). El poema en prosa en España (1940-1990). Estudio y antología. Tesis Doctoral dirigida por el profesor Andrés Sánchez Robayna. La Laguna: Universidad de La Laguna. Departamento de Filología Española. Facultad de Filología (inédita).

— (2000). "Panorama del poema en prosa en Canarias (Estudio y antología)". Estudios Canarios XLIV, 321-386.

- (2002a). "La poesía en prosa de José Ángel Valente”. Revista de Filología 20, 161176.

- (2002b). "La poesía en prosa en la primera mitad del siglo XX". En Wenceslao Fernández Flórez y su tiempo, Fidel López Criado (ed.), 299-308. A Coruña: Ayuntamiento de A Coruña.

Millán AlbA, José Antonio (1989). "Algunos aspectos del poema en prosa y las categorías del lirismo contemporáneo". En Imágenes de Francia en las Letras Hispánicas, Francisco Lafarga (ed.), 29-36. Barcelona: PPU.

Monroe, Jonathan (1987). A Poverty of Objects. The Prose Poem and the Politics of Genre. Ithaca and London: Cornell University Press.

Moreau, Pierre (1969). La tradition française du poème en prose avant Baudelaire. París: Archives des lettres modernes.

MurPhy, Margueritte S. (1992). A Tradition of Subversion. The Prose Poem in English from Wilde to Ashbery. Amherst: The University of Massachusetts Press.

PARENT, Monique (1960). Saint-John Perse et quelques devanciers. Études sur le poème en prose. París: Libraire C. Klincksieck.

RozAS, Juan Manuel (1973). Introducción a José Martínez Ruiz (Azorín), Castilla, 7-75. Barcelona: Labor.

Ruiz Casanova, José Francisco (1990a). "La última generación poética española". Anthropos 110-111, XIV-XVI.

SANDRAS, Michel (1995). Lire le poème en prose. París: Dunod. 
Silliman, Ron (1986). "New Prose, New Prose Poem”. En Postmodern Fiction. A BioBibliographical Guide, Larry McCaffery (ed.), 157-174. New York: Greenwood Press.

- (1987). The New Sentence. New York: Roof.

Sobejano, Gonzalo (1990). "Poema en prosa y dimensión del recuerdo en La lámpara maravillosa". En La ínsula sin nombre: Homenaje a Nilita Vientos Gastón, José Luis Cano y Enrique Canito, Eugenio Suárez-Galbán (ed.), 25-39. Madrid: Orígenes.

SimON, John (1987). The Prose Poem as Genre in Nineteenth-Century European Literature. New York \& London: Garland.

Terdiman, Richard (1985). Discourse / Counter-Discourse: The Theory and Practice of Symbolic Resistance in Nineteenth-Century France. Ithaca, N. Y.: Cornell University Press.

VADE, Yves (1996). Le poème en prose et ses territoires. París: Belin.

Utrera Torremocha, María Victoria (1999). Teoría del poema en prosa. Sevilla: Universidad de Sevilla.

VillenA, Luis Antonio de (1999). "Variedad del poema en prosa" (Reseña a Poemas en prosa (1965-1994), de Ángel Crespo). El Mundo, 27 de febrero, 18.

VinCENT-MunNIA, Natalie (1996). Les premieres poèmes en prose: généalogie d'un genre. Dans la première moitié du dix-neuvième siècle français. París: Champion. 